\title{
Geofísica na prospecção de granito para brita em ambiente amazônico (NE do Pará)
}

Lúcia Maria da Costa e Silva, Bruce Fabini Franco Chiba, Jorge Armando Freitas do Amaral, Abraão Fernando Figueira de Melo - Serviço Geológico do Brasil/Superintendência Belém

\section{Copyright 2018, SBGf - Sociedade Brasileira de Geofísica}

Este texto foi preparado para a apresentação no VIII Simpósio Brasileiro de Geofísica, Salinópolis, 18 a 20 de setembro de 2018. Seu conteúdo foi revisado pelo Comitê Técnico do VIII SimBGf, mas não necessariamente representa a opinião da SBGf ou de seus associados. É proibida a reprodução total ou parcial deste material para propósitos comerciais sem prévia autorização da SBGf.

\section{Resumo}

A obliteração do embasamento pelo manto de intemperismo, por um lado, e a necessidade de brita para construção civil no Estado do Pará, por outro, motivou o Serviço Geológico do Brasil/Superintendência Regional de Belém (SGB/SUREG-BE) a testar diferentes metodologias geofísicas na delimitação de ocorrências de granitos de mapeamento impreciso até $20 \mathrm{~m}$ de profundidade. A integração dos resultados até o presente momento mostrou que, dos dados aerolevantados, o canal do potássio é o guia principal, bem como que todos os métodos utilizados no follow up terrestre, em especial a Eletrorresistividade, apontam para embasamento caracterizado por falhamentos verticais de rejeito significativo anteriormente não identificados, que diminuem a área provável de lavra.

\section{Introdução}

A demanda iminente por empreendimentos logísticos planejados pelos Governos Federal e Estadual no Estado do Pará, dentre eles a expansão do complexo portuário e rodoviário/ferroviário, e o fato que a única mina de exploração de brita em todo NE do estado, no Granito Tracuateua (Mineração Santa Mônica), não é suficiente para atender a demanda atual, voltou a atenção do Serviço Geológico do Brasil (SGB) em consonância com o plano de mineração do estado do Pará (2014-2030), para a utilização da Geofísica na prospecção de corpos graníticos (Costa, 2017). *

$\mathrm{Na}$ prospecção desse tipo de material conhecido como de classe II, que é o alvo da chamada Mineração Social, o uso da Geofísica não é (re)conhecido ou tomado como atraente por causa do tempo e custo que acarreta em relação a sondagens mecânicas rasas, relativamente rápidas e de custo baixo, quando comparadas às sondagens profundas exigidas pelos demais tipos de mineração. Ocasionalmente, apenas dados geofísicos aerolevantados (em especial, os radiométricos) são utilizados.

A maior parte da Amazônia, contudo, é geologicamente muito antiga e palco de diversos ciclos tectônicos. O estudo geológico da Amazônia é, portanto, tarefa árdua. A região, ademais, abriga áreas ínvias ou de difícil acesso. O maior obstáculo a esse estudo, contudo, está relacionado ao clima da região marcado por elevadas temperaturas e índice pluviométrico, que provoca intenso intemperismo e o subsequente desenvolvimento de espesso manto de intemperismo. São dezenas a poucas centenas de metros de manto de intemperismo que obliteram vestígios do embasamento geológico e afloramentos, consequentemente, são raros. Daí o interesse em avaliar a utilidade de trabalhos geofísicos na prospecção de interesse da Mineração Social, embora a profundidade não ultrapasse $20 \mathrm{~m}$ e a geofísica não seja aplicada.

A empresa realizou anteriormente investigação por meio do método geofísico conhecido como GPR (do inglês ground penetrating radar) de depósitos de areia para construção em quatro áreas da região de Macapá, ao sul do Amapá, obtendo resultados relevantes (Lago et al., 2016).

Este trabalho reporta testes com diferentes métodos geofísicos realizados pelo SGB/SUREG-BE com a integração de resultados em andamento, a fim de eleger aqueles capazes de dar a maior contribuição dentro do ambiente geológico considerado em escala de alta produtividade para a delimitação de ocorrência de granito até a profundidade possível de lavra (cerca de $20 \mathrm{~m}$ de profundidade).

\section{Área}

O trabalho foi realizado no nordeste do Pará, em área localizada a $150 \mathrm{~km}$ de Belém, que compreende os corpos graníticos Ney Peixoto, Jonasa e Ourém, mapeados na folha Capitão Poço/SA.23-V-C-V $(1: 100.000)$, mostrada na figura 1. Amostras de afloramentos obtidas anteriormente ao trabalho evidenciam que o limite dos corpos é impreciso.

Esses granitóides são colisionais, têm origem em magma tipo $S$ relacionado à refusão da crosta continental. $O$ Granito Jonasa e o Granito Ourém são do Paleoproterozóico (cerca de $2 \mathrm{Ga}$ ), enquanto o Granito Ney Peixoto tem relação com orogênese muito mais recente, Neoproterozóica (549 Ma) (Klein et al. 2015, Villas \& Souza, 2007).

\section{Aerolevantamento e follow up terrestre}

Primeiramente, foram analisados dados aerogeofísicos levantados pelo Projeto Aerogeofísico Gurupi (CPRM 2009), após tratamento com Oasis Montaj (Geosoft). Os dados radiométricos foram apresentados sob a forma de concentração de equivalente de tório, urânio e potássio, dosagem da contagem total e ternário. Os dados magnéticos, por sua vez, foram tratados com as técnicas 
de realce de anomalia (Milligan \& Gun, 1997) amplitude do sinal analítico (ASA) e primeira derivada.

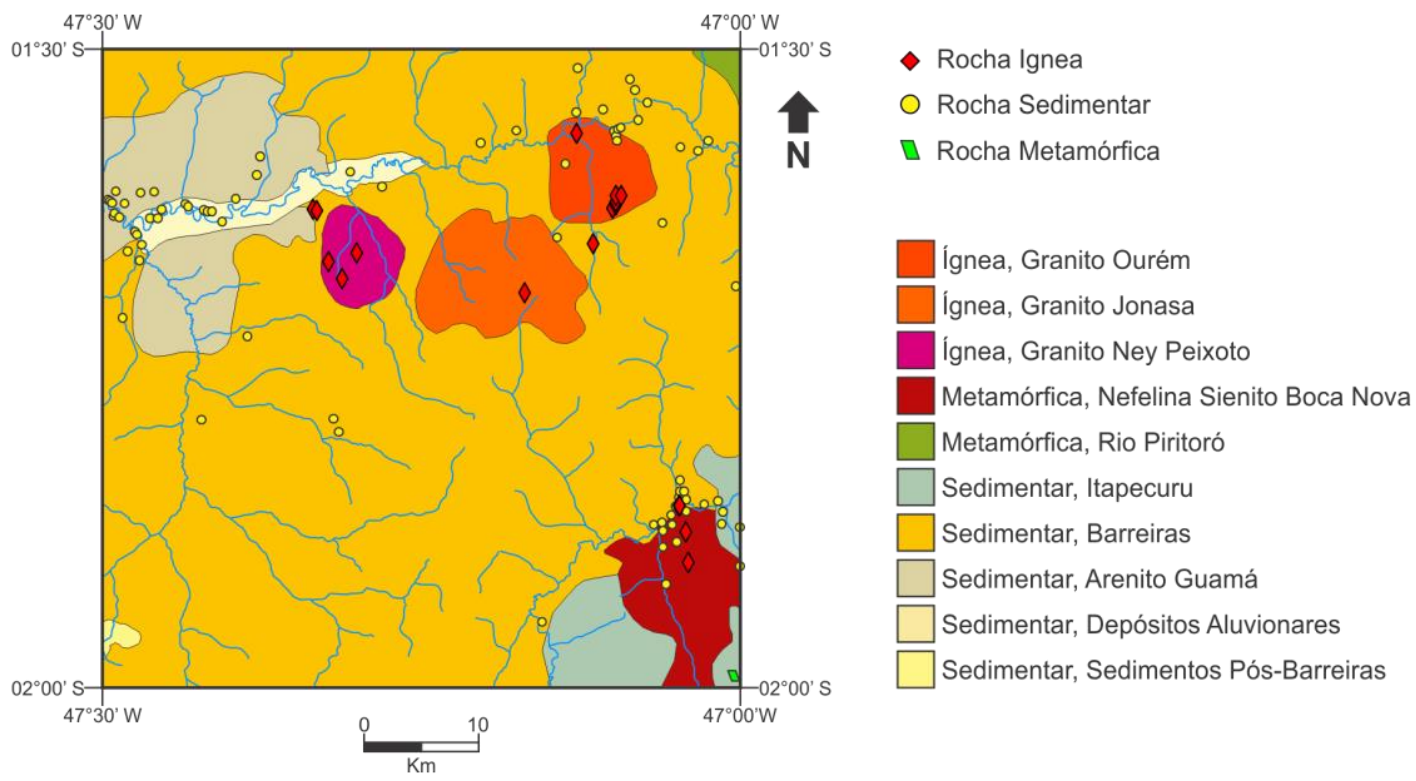

Figura 1 - Mapa Geológico Folha Capitão Poço com a localização de amostras de afloramentos classificadas quanto à gênese coletadas por E.L. Klein e M.H.B. Leão (Serviço Geológico do Brasil). Os limites dos granitóides é impreciso.

Essa análise, integrada com dados existentes, permitiu selecionar alvos para o follow up de geofísica terrestre com GPR, Radiometria e Eletrorresistividade, métodos tratados por Adams \& Gasparini (970), Orellana (1972) e Annan (1971), respectivamente. O GPR foi realizado ao longo de trechos de linhas de investigação com equipamento dotado de antenas de $100 \mathrm{MHz}$ da empresa MALÅ Geoscience (Suécia). A investigação radiométrica foi realizada ao longo de linhas em modo contínuo distante do terreno com Cintilometria e, em pontos selecionados, com Espectrometria no nível do terreno, usando-se o equipamento RS-125 da Radiation Solutions (Canadá). Finalmente, a Eletrorresistividade foi utilizada em Sondagens Elétricas Verticais (SEVs) no centro das linhas cobertas por Tomografia Elétrica, obtida com $10 \mathrm{~m}$ entre as 72 estações com o resistivímetro SyscalPro e Switch72 ambos fabricados pela Iris Instruments (França). Os dados GPR foram processados com 0 programa ReflexW. As sondagens elétricas obtidas com o arranjo Shclumberger foram interpretadas com o auxílio do programa IPI2Win e a tomografia levantada com o arranjo Wenner-Schlumberger.

\section{Integração dos Resultados}

A integração dos resultados geofísicos, a luz de quatro sondagens mecânicas e refinamento do mapeamento geológico, evidenciaram que, dentre os dados aerolevantados, são os dados para o potássio os melhores guias para o follow up, ainda que a solubilidade caia na seguinte ordem: potássio, urânio e tório. Em outras palavras, ainda que o potássio seja transportado a longas distâncias, devido ao clima, mobilizam-se também urânio e mesmo o tório, de modo que a presença de elevado potássio revela a presença de rocha fresca, (no caso; os granitóides).

A figura 2 mostra o mapa de isocontornos obtidos para o potássio. O domínio de maior extensão areal é caracterizado pela alternância de valores altos e baixos de potássio, com predomínio dos valores altos sobre os baixos crescendo de leste para oeste. Este domínio é seccionado por domínio de elevado potássio que coincide com a drenagem, em que se destaca o rio Guamá ENEWSW. Ocorre ainda um domínio de pequena expressão, correspondente a pequenas áreas com elevada concentração de potássio dentro do primeiro domínio, que aparecem a Sul do rio Guamá, sem conexão com a drenagem. Uma dessas áreas coincide com a área do Hotel Fazenda Cachoeira, mostrada na figura. Esse hotel foi palco de lavra pretérita de granito, ainda que não mapeado no mapa geológico. As outras duas áreas são identificadas a Norte e a Oeste da primeira, dentro do contorno do que seriam os granitos Ourém e Ney Peixoto, respectivamente. Essas duas áreas ricas em potássio aparecem indicadas por seta na figura 1 e 


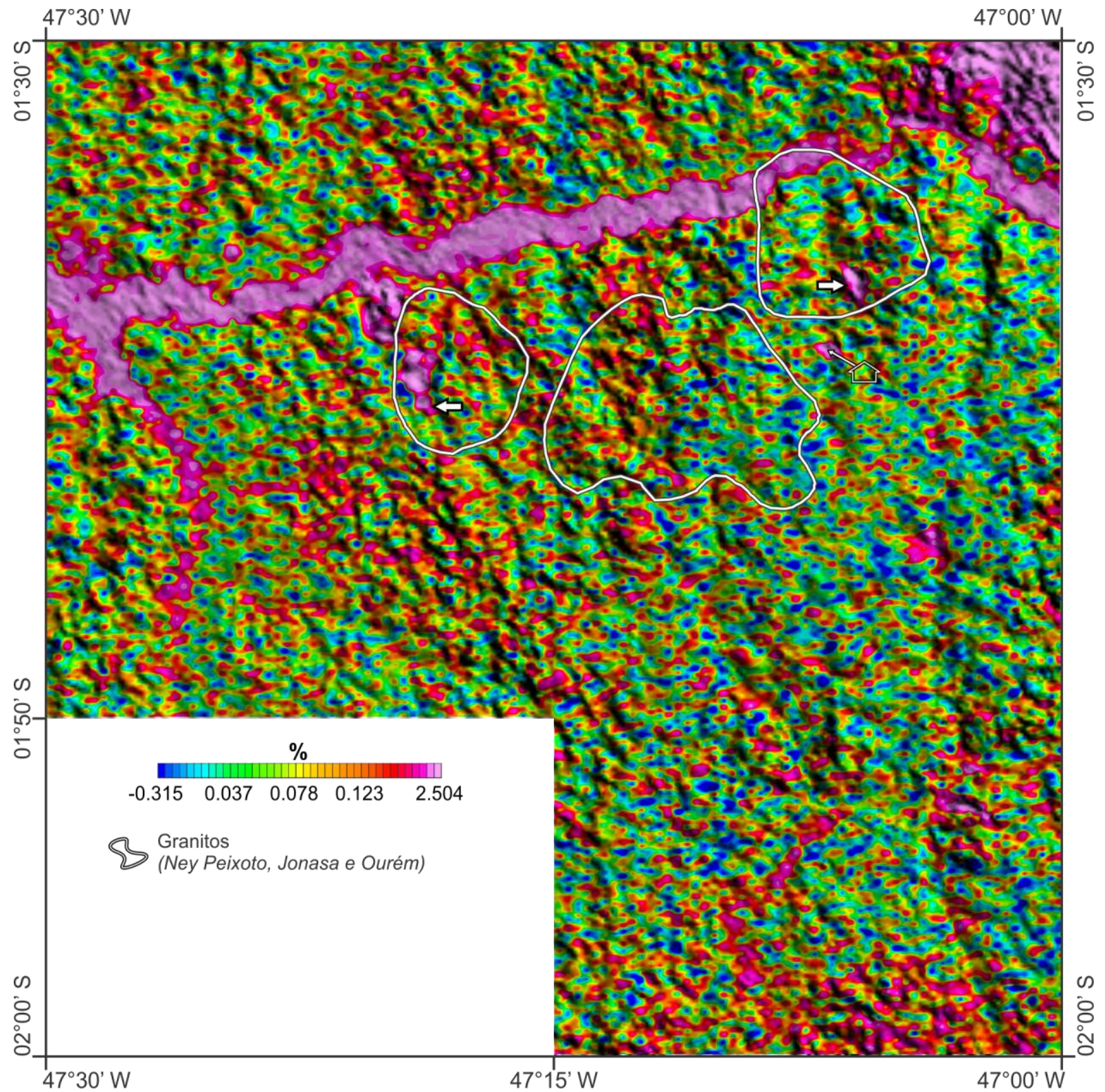

Figura 2 - Mapa de isocontornos de potássio. Lavra hoje transformada em Hotel mostrada na figura fora dos limites dos corpos graníticos (em branco) e igual assinatura a norte e a leste assinada com flechas.

correspondem a afloramentos de granito na área correspondente ao granitóide Ourém e Ney Peixoto. Não foi encontrado afloramento do corpo Jonasa no setor central investigado Os levantamentos terrestres, por outro lado, mostraram que a cintilometria contínua por linha com a seleção de pontos para a Espectrometria auxiliam sobremaneira a encontrar porções subaflorantes do granito. A Sondagem Elétrica Vertical e a Tomografia Elétrica, por sua vez, permitiram modificar a hipótese de corpo granítico extenso coberto por manto de intemperismo para granitóides seccionados por falhas aproximadamente verticais, como mostrado na figura 3 . Finalmente, a utilidade do GPR mostrou-se reduzida porque os falhamento mostram rejeito considerável, tal que convivem a poucos metros granito aflorante e nenhum vestígio no radargrama até profundidades de cerca de $10 \mathrm{~m}$, que foi a profundidade alcançada devido à atenuação do sinal pela presença de argila derivada do intemperismo até mesmo dos próprios granitóides. 


\section{Discussão e Conclusões}

Os testes realizados indicam que os métodos geofísicos de Radiometria e Eletrorresistividade se mostram bastante positivos com respeito à prospecção de granitos para uso na construção civil. A aplicação desses métodos se mostrou bastante atraente, inclusive, com respeito ao aspecto econômico, considerando a relativamente baixa relação custo benefício.

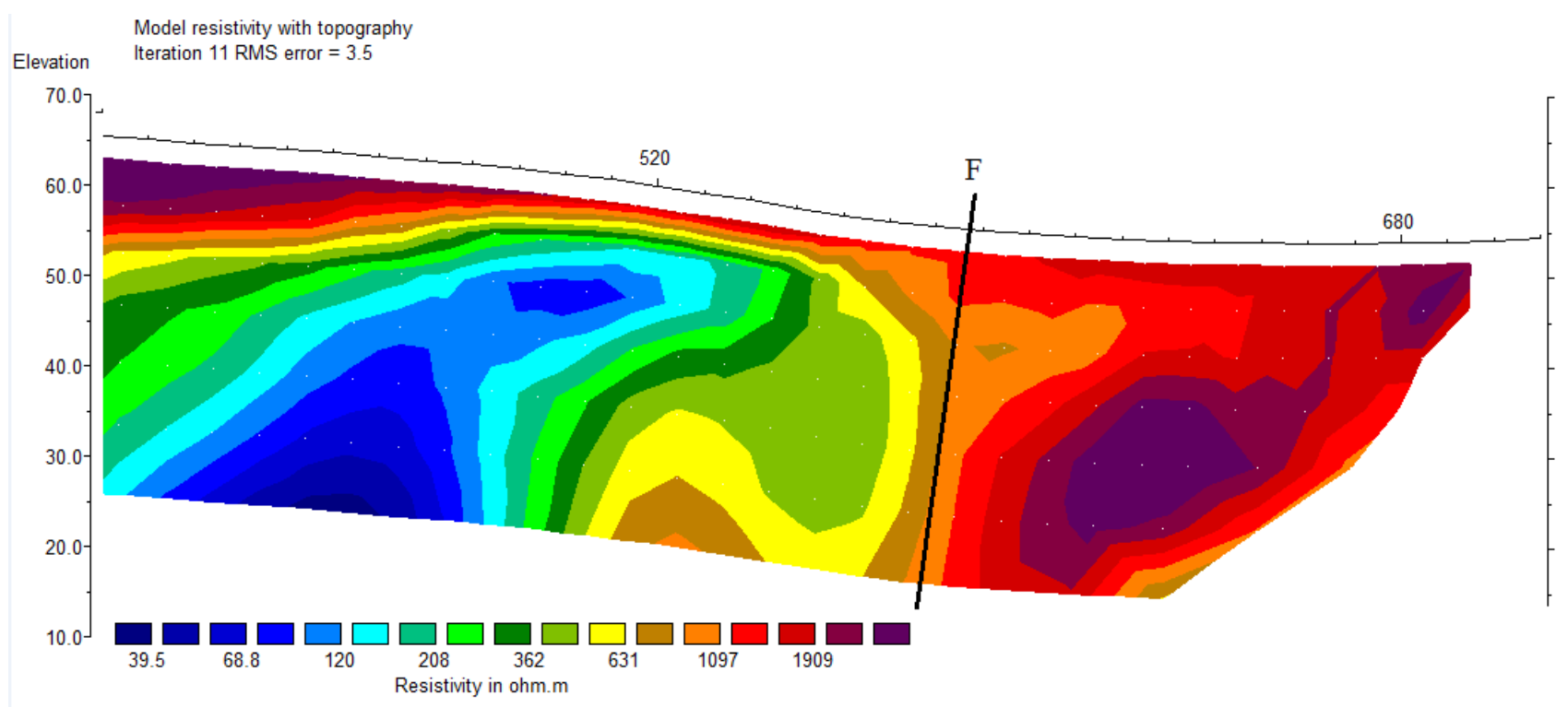

Figura 3 - Trecho de modelo de distribuição de resistividade obtido por meio de inversão a partir de Imageamento Elétrico ao longo de linha W-E na borda da assinatura do canal de potássio marcada com seta dentro do limite do granito Ourém. F: falha separando ocorrência de granito à direita.

\section{Agradecimentos}

Aos técnicos seniores de Geofísica e Sondagem Mecânica Paulo Sergio Ferreira dos Santos, Avelino Alves de Moraes, Sebastião Gouveia Benjamin e Antônio Pereira de Araújo Junior pelo empenho no trabalho de campo.

\section{Referências}

ADAMS, J. A. S.; GASPARINI, P. 1970. Gamma-ray spectrometry of rocks. New York: Elsevier. 295 p.

ALMEIDA, F. F. M. de, 1969. Diferenciação tectônica da Plataforma Brasileira (Tectonic differentiation of the Brazilian Platform). Proceedings 33rd. Brazilian Geological Congress, Salvador(BA), Brazil, vol. 1: 29-46.

ANNAN, A.P. 2001. Ground Penetrating Radar Workshop Notes. Ontario, sensor \& Software Inc. 192 p.

COSTA, L.T. R. 2017. Pesquisa de Áreas Potenciais para Brita no NE do Pará. CPRM, SUREG-BE. 7 p.

CPRM, 2009. Programa Geologia do Brasil (PGB) Projeto Aerogeofísico Gurupi. Relatório Final do Levantamento e Processamento dos Dados
Magnetométricos e Gamaespectrométricos. MME/SGM/CPRM, RJ. V. I (Texto Técnico), 140 p.

LAGO, A. L.; BORGES, W. R. \& TEIXEIRA, S. G. 2016. In: MELO, A. F. F.; OLIVEIRA, J. G. F \& TEIXEIRA, S. G. Projeto Materiais de Construção da Região de Macapá Estado do Amapá. Cap. 4: Utilização de GPR (Radar de Penetração no Solo) para Estudo dos Depósitos de Areia. P: 61-78. Belém: CPRM - Serviço Geológico do Brasil.

KLEIN, E. L.; LOPES, E. C. S. \& CHAVES, C.L. 2015. Geologia e Recursos Minerais da Folha Santa Luzia do Pará - SA.23-V-C-VI, Estado do Pará, Escala 1:100.000. Belém: CPRM - Serviço Geológico do Brasil. XXX p.: il. Color + 1 CD-ROM.

MILLIGAN, P. R. \& GUNN, P.J. 1997. Enhancement and presentation of airborne geophysical data. AGSO Journal of Australian Geology \& Geophysics, 17(2): 63-75.

ORELLANA E. 1972. Prospeccion geoelectrica en corriente continua. Madrid, Ed. Paraninfo, Biblioteca Tecnica Philips, $523 \mathrm{p}$.

VILLAS, R. N. N.; SOUSA, F. D. S. 2007. O granito de duas micas Ney Peixoto, nordeste do Pará: aspectos petrológicos e significado tectônico. Revista Brasileira de Geociências, 37(1): p. 3-16. 